\title{
A System Dynamics Modeling and Computer-based Simulation in Forecasting Long-term Sufficiency: A Philippine Chicken Meat Sector Case Study
}

\author{
Ma. Theresa M. Espino \\ Engineering Graduate Program \\ School of Engineering \\ University of San Carlos \\ Cebu City, Philippines and \\ Department of Industrial Engineering \\ Ateneo de Davao University \\ Davao City, Philippines \\ mtmespino@addu.edu.ph
}

\author{
Luzvisminda M. Bellotindos \\ Engineering Graduate Program \\ School of Engineering \\ University of San Carlos \\ Cebu City, Philippines and \\ Center for Research in Energy Systems and Technologies \\ University of San Carlos \\ Cebu City, Philippines \\ lmbellotindos@usc.ed
}

\begin{abstract}
As the human population continues to grow, the global growth of the livestock sector will continue to rise as well. In the Philippines, the demand for chicken meat is projected to triple by 2050. In this study, the increasing consumption and long-term sufficiency were evaluated with the use of the system dynamics concept. With system modeling and computer-based simulation techniques, the available data on chicken meat supply chain were processed considering that factors behave dynamically. The simulated model facilitated the forecasting of key variables which may drop sufficiency from $87 \%$ in 2015 to $60 \%$ by 2050 if no proper actions take place in the areas of production and consumption. As a whole, this study developed and demonstrated preliminary system dynamics-based and computer basedapproaches in order to understand the chicken meat sector. This showed that a dynamic systems-based paradigm shift in food and agricultural systems analysis can help address operational and strategic issues regarding food security.
\end{abstract}

Keywords-forecasting; system dynamics modeling; computerbased simulation; Philippine chicken meat; sufficiency

\section{INTRODUCTION}

As human population continues to grow by an approximately annual $1.1 \%$ percentage, the growth of livestock sector will continue to rise as well. The demand for meat is projected to grow by $70 \%$ in 2050 with 2005 as baseline. The poultry sector, which is basically chicken meat (CM) has the highest growth among meats at $121 \%$ [1]. It is a challenge for poultry sector to satisfy the demand and to align to the mandate on Sustainable Development Goals (SDG). The sector has to comply primarily to food security as expressed in SDG \#2 Zero Hunger [2]. One of the tools in achieving this is addressing food self-sufficiency, which is the ability to meet consumption needs, especially for staple food items such as meat, from domestic production rather than by importing. In addressing food security or food sufficiency, reliable forecasting is the foundation of all warning systems, in order to give decisionmakers enough time to plan and respond to red flag warnings. Corresponding author: M. T. M. Espino
Forecasting has to have a high degree of reliability to avoid false alarms. Traditional popular forecasting techniques such as linear regression and multiple regression are used to examine the relationship between independent variable(s) and a dependent variable [3-6]. Their usefulness is considerably acceptable for simple forecasting requirements. However, the outcomes are sometimes compromised, especially when the data are incomplete and correlation might be regarded as causation.

To consider causation, System Dynamics (SD) approach is more advantageous. SD is based on the synthesis of various concepts including operating theory, system theory, control theory, information feedback theory, decision-making theory, mechanical systems theory, and computer science. SD can model the system and analyze the system's behavior given the desired parameters over time [7]. In contrast to traditional forecasting, SD models are more flexible in predicting complex phenomena due to their dynamic behavior [7, 8]. The SD models are more reliable since they can estimate the sensitivity of results to variables and employ stronger scenarios with the impact of significant changes in strategies or interventions. The process of establishing the model may seem complex at the initial model build-up stage. However, rigor and results can be more significant, especially in forecasting variables in dynamic systems. SD studies have been done in various industries $[8,9]$ and across agricultural and natural resources $[10,11]$. On food supply chain systems, SD has already been applied in rice production [12-14] and food supply $[15,16]$, which makes it appropriate for the poultry sector. Though these studies were done in food agricultural systems, they were not anchored to specific timelines of long-terms plans and sustainability goals on the respective countries.

\section{PHILIPPINE CHICKEN MEAT SECTOR}

In Philippines, chicken is the most progressive animal enterprise. In 2017, the total chicken meat volume production 
in Philippines was 1,344.3 thousand metric tons (TMT). The industry volume is growing at $3.6 \%$ per annum during the last five years. A total inventory of 140.20 million birds for meat production has been recorded [17]. In terms of scale, the industry is characterized by "backyard" and "commercial" farms/installations. As described by Sikap/Strive Foundation, rural families run the typical backyard farms, which comprise around 100 birds of native or improved breeds, which are raised primarily for their own consumption. On the other hand, commercial farms have at least 1,000 broilers, or combinations of at least 100 broilers and 100 layers [18]. The per capita consumption was $12.7 \mathrm{~kg}$ in 2017 , a $47 \%$ rise over a decade. The increase in local consumption is reported to be attributed to the changes in lifestyle, income and urbanization [19]. At present, the government tracks sufficiency expressed in SelfSufficiency Ratio (SSR), or the equivalent Self-Sufficiency Level (SSL), an indicator of adequacy of local food production to satisfy the demand of the population. For chicken meat, the SSL at a national level was $92.82 \%$ in 2013 but declined to $84.67 \%$ in 2016 which is the lowest over a decade. The drop of $8.8 \%$ showed the widening gap of production and consumption. Moreover, this indicated that around $15 \%$ of the demand was not satisfied in 2016 by local production, but was fulfilled through importation. However, SSL improved back to $96.1 \%$ in 2017 with the big improvement in local production [20]. Total supply is augmented through importations. It registered 55.49 TMT in 2017. It has been increasing by 20132016 but declined in 2017, which was a manifestation that local production improved [21]. Total production also utilized exports. The lowest level of exports was in 2017 at 355 metric tons which continued the downtrend since 2015 [17].

In terms of cost of production, the highest cost driver is feeds in both production systems. It accounts for about approximately 65 to $70 \%$ of total live broiler production [22]. Soybean Meal (SBM) is the major source of protein in feeds production. At present there is a limited soybean local production which only serves $8 \%$ of the country's requirements [23]. On the other hand, most feed formulation uses maize as a primary source for energy. Based on consolidated data in Global Livestock Environmental Assessment Model (GLEAM), the baseline mix for broilers is $71 \%$ maize, $27 \%$ SBM, and $2 \%$ other additives. Based on gathered field data, the average feed across stages is comprised of 51\% maize, $25 \%$ SBM, 9\% rice bran, 5\% fish meal, 4\% copra meal, $2 \%$ vegetable oil, and $4 \%$ other additives. For backyard production the baseline feed is $40 \%$ swill, $17.7 \%$ grass, $6 \%$ cassava, $4.4 \%$ maize, and the rest come from agriculture by-products [24]. However, field data showed that there is no comparable mix since different backyard operations have different feedings based on locale availability, practices, and capacity. The imported feed ingredients have more impact on broiler production. In terms of feeding, the average feed consumption is $2-2.5 \mathrm{kgs}$ per bird over a 30 -day average rearing period while the amount is $3-3.9 \mathrm{kgs}$ per bird for backyard chickens over a period of 90 days. Another challenge to improve in local production is technology. Changes in production practices have increased productivity and capacity. For chicken production, this is represented by the broiler inventory and native breed inventory which describe the method and scale of production.
Based on field and GLEAM data, the average mortality rate is between $2-5 \%$ for broiler production, with a marketable average live weight of $1.6-1.2 \mathrm{~kg}$ and carcass weight of 1.2 $1.0 \mathrm{~kg}$ over 30 days. On the other hand, the native breed inventory characterizes the typical backyard farms. Backyard chicken would achieve a live weight of $1.3-0.9 \mathrm{~kg}$ and a carcass weight of $1-0.70 \mathrm{~kg}$ over a period of 90 days [18].

An extensive review on the related literature in Philippines showed that no concrete studies have been done regarding meat production and consumption from a long-term sufficiency or sustainability perspective. This paper aims to answer the questions of "how do we evaluate the long term-sufficiency?" and "what are the factors that affect the long-term sufficiency of the Philippine chicken meat sector". With those in mind, the following key objectives are namely: to establish a dynamic model on the impact of increasing consumption to local production, to simulate consumption and production projections up to 2050, and to evaluate forecasts and their implications to sufficiency. The results of this paper can evaluate the model in terms of long-term sufficiency, sustainability, and stability to satisfy local consumption in the future in the Philippine poultry sector. This can be used as a reference for planning, identifying opportunities, and conducting relevant researches to improve chicken meat production in view of achieving SDG 2 by 2050, the timeframe where SDGs and Paris agreement are referred to. The model can help agricultural decision-makers and government agencies to come up with better programs to promote local agricultural economy and to provide better policies and programs to address issues related to food security.

\section{Methodology}

\section{A. Materials}

Statistical data were taken from Philippine Statistics Office, the official web-based system for food and agricultural statistical information in Philippines [17] and the global meat consumption per country by OECD [1]. Production related data were taken from the related literature and actual fieldwork and experiments conducted by the authors. Regarding software, Vensim, a simulation software for Causal Loop Diagram (CLD) [25] and STELLA (Systems Thinking for Education and Research) for Stock and Flow Diagram (SFD) [26] were utilized.

\section{B. Methods}

The SD model in this study was primarily anchored on the methodology presented in [7] that includes a three-step process: (a) formulation of the dynamic hypothesis, (b) implementation of the simulation, and (c) testing and validation. This was further expounded with specific steps as presented in Figure 1, which serves as the framework of this study. This study is limited and focused to the forecasting of related variables and their implications by 2050 . No policies or proposed action plans will be integrated in the model to demonstrate other functionalities. In ensuring a high level of accuracy of the model, validation was done with Mean Absolute Percentage Error (MAPE) [27, 28], a simple yet reliable statistical measure on forecast accuracy and error of models, as demonstrated in [29-31]. Forecasting with less than 10\% MAPE is considered 
as highly accurate, with $10-20 \%$ as good, with $20-50 \%$ as reasonable and forecasting with MAPE greater than $50 \%$ is considered inaccurate [32]. Validating the model was an iterative stage until the desired MAPE was achieved.

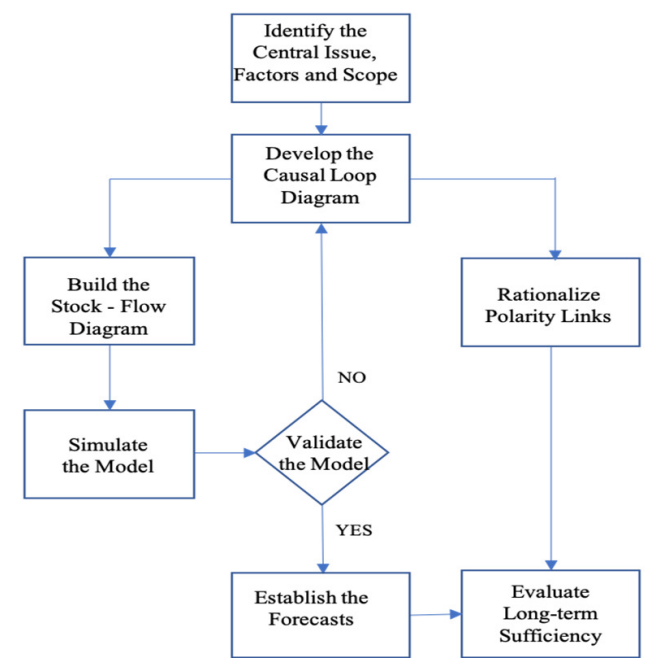

Fig. 1. Framework of system modeling and simulation in forecasting longterm sufficiency

\section{RESULTS AND DISCUSSION}

\section{A. Dynamic Hypothesis}

The analysis was centered on the factors that influence local production and consumption. Production is basically driven by the technology or processes applied to the two methods of production, broiler and backyard, as quantified in their respective inventories. On the other hand, consumption is driven by the population and per capita consumption. The dynamic hypothesis is illustrated in the CLP and further broken down to SFD. The timeframe considered is up to 2050, aligned to the timeframe of SDGs and Paris agreement.

\section{1) Causal Loop Diagram (CLD)}

CLD is the visual representation of how variables in a system interact and interrelate. Auxiliary variables were included in the CLD that were simply calculations based on the stock and flows with some discrete event and agent-based modeling capabilities. To complete the CLD, the polarity links were rationalized among factors, which were either positive $(+)$ or negative (-). This signified the influence of one variable to the other relevant variables. In Figure 2 the CLD of Chicken Meat Sufficiency is shown. The diagram was anchored on SSL, the state when local production satisfies local consumption. On the demand side, local consumption is driven by population and per capita chicken consumption. While on the supply side, local production is driven by both broiler and backyard production, which are influenced by their respective yield and inventory. Surplus is included in the diagram, which is ideally the determinant for exportation should there be excesses and for importation should there be deficits in the supply chain.

2) Stock and Flow Diagram (SFD)
After CLD, model building was done for the SFD. To ensure that stock and flows were defined accordingly, units were checked and equations were specified. There were 5 stocks identified, namely population, chicken per capita consumption, CM, broiler inventory, and backyard chicken inventory as shown in Figure 3. The core stock in the system is $\mathrm{CM}$, which is influenced by its inflow converter CM supply and outflow converter CM utilization. Projection on population growth is available. For the other 3 growth rates, projections were based on 20 year historical performance data (19982017). Included in the SFD are auxiliary variables on SBM usage and maize usage which are relevant in the study to evaluate the whole context of sufficiency given that they are imported production inputs.

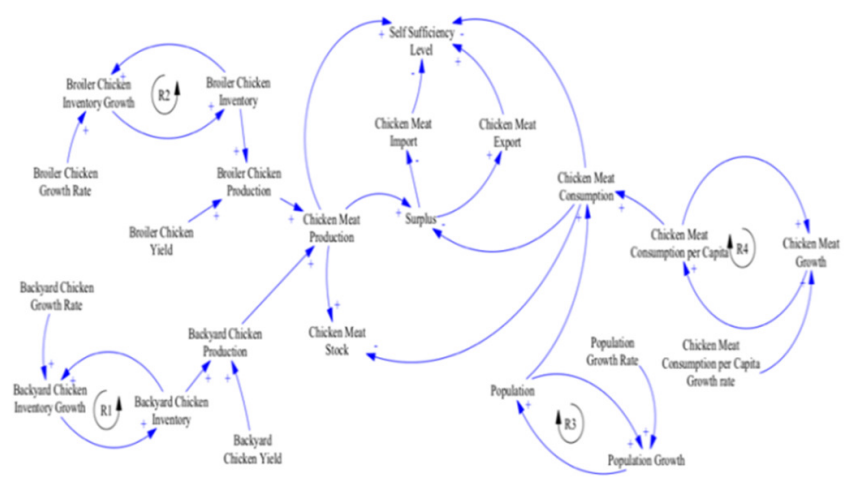

Fig. 2. Cause loop diagram of chicken meat production

\section{B. Simulation}

To proceed with forecasting, the 4 relevant growth rate data were used as inputs in STELLA. With the equations set in the computer software, the values of the various variables in were generated from the equations in SFD indicated in Figure 4.

\section{Validation}

To validate the model, the actual consumption and production from 2008-2017 were compared to their equivalent simulated data as shown in Table I. MAPE is $8.5 \%$ for consumption and $2.8 \%$ for production, indicating that the whole model can be considered acceptable with a high level of accuracy.

\section{Forecasting}

With the validated model, forecasts can then be generated from the SFD model. In Figure 5, is the Supply Utilization Accounts summary of actual and projected variables from 2010 to 2050 is presented. It is indicated that sufficiency level will drop to $60 \%$ by 2050 , if no interventions take place.

\section{E. Implications to Long-term Sufficiency}

The model showed that consumption will almost triple. Also, it can be seen that there is no room for exportation in order to serve its own requirements. Moreover, $40 \%$ of the requirements will be satisfied from chicken meat importations. This can be a red flag, knowing that chicken price has been rapidly increasing in the global market. 


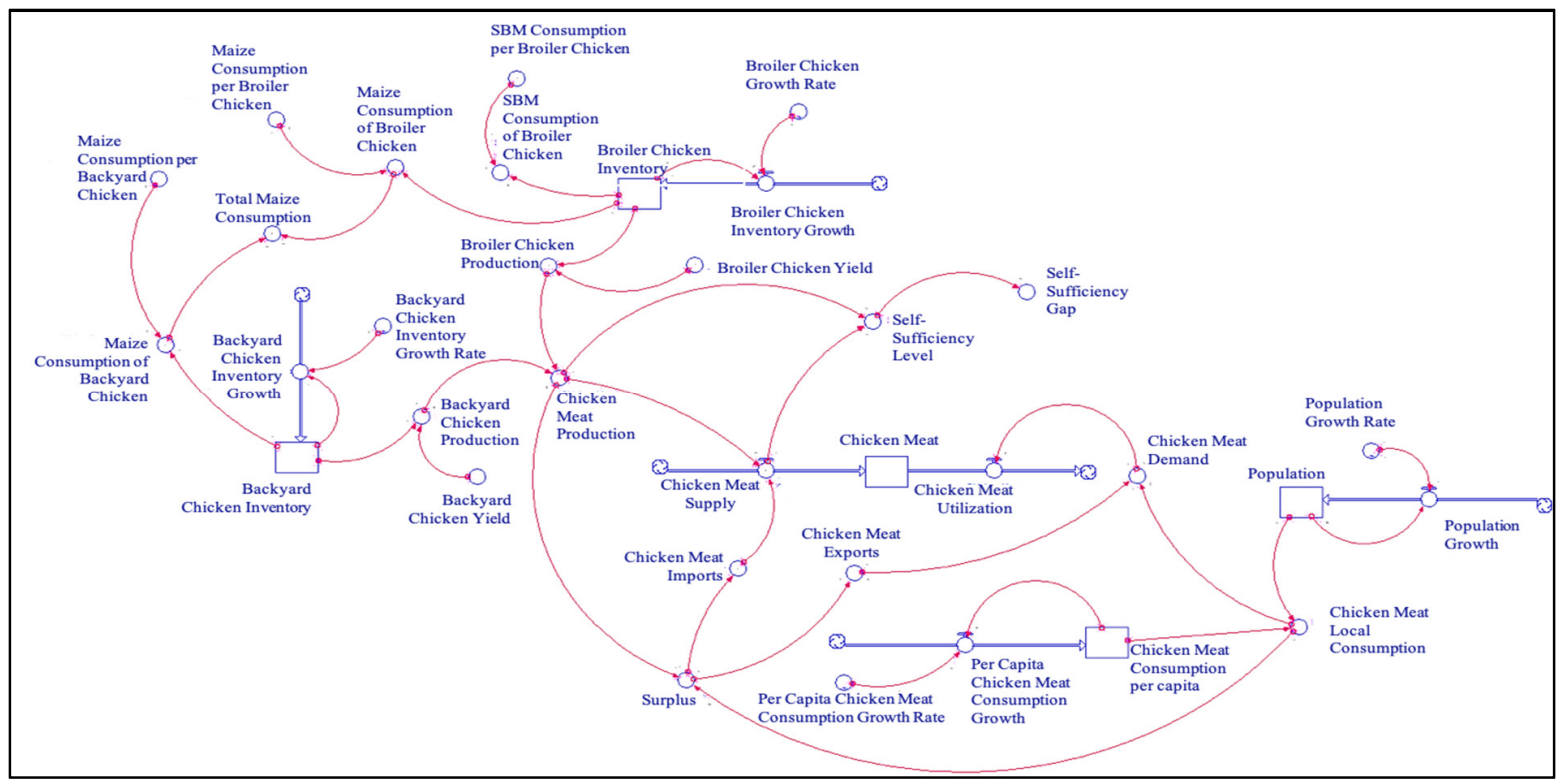

Fig. 3. Stock flow diagram of chicken meat production

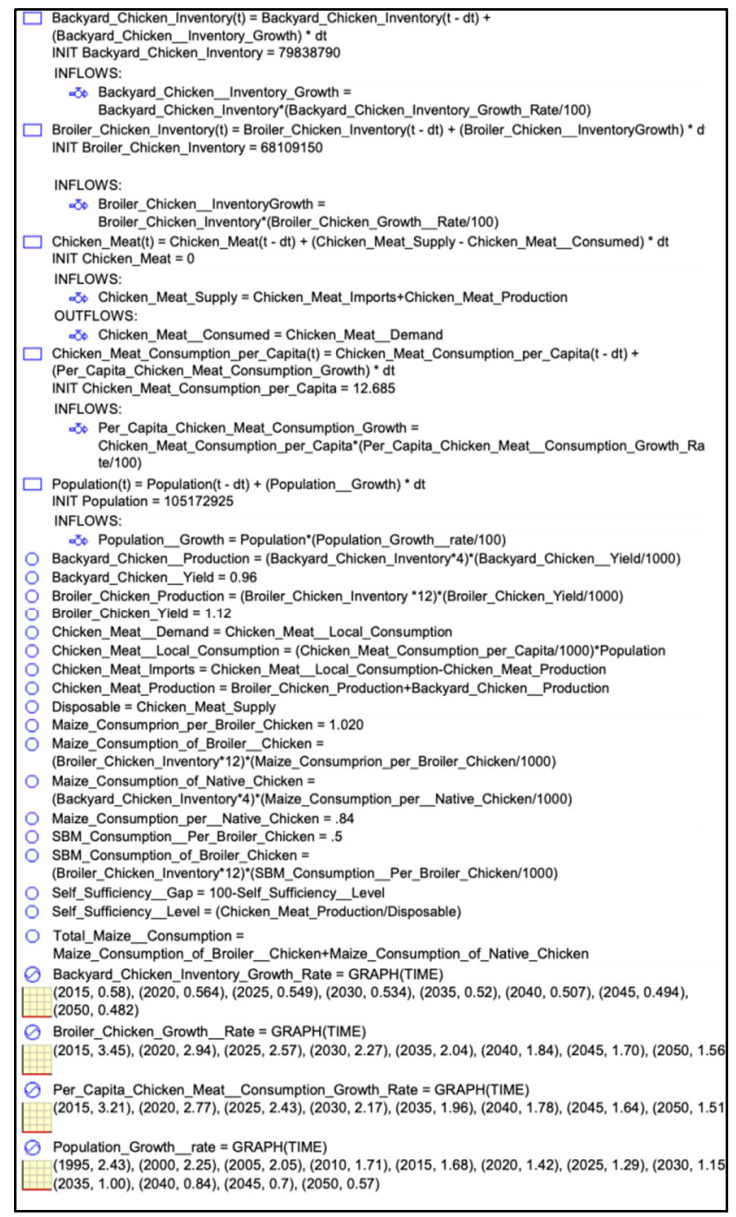

Fig. 4. Simulation equations of stock and flow diagram

In the production side, broiler production is the driver, currently contributing at $75 \%$ of the volume and will continue and rise to $84 \%$ by 2050 as shown in Figure 6. In Figure 7, broiler inventory versus backyard chicken is shown. We can see that by 2025 , broiler will outpace backyard production. Further analysis for broiler chicken production and feeds usage may be necessary since the country cannot claim absolute sufficiency given that the main feed ingredients are imported, especially SBM and maize. With the projections, the importations of these two ingredients are expected to rise exponentially as shown in Figure 8. This can be another red flag for instability in terms of resource management, operational efficiency, and cost control on imported inputs especially for broiler chicken.

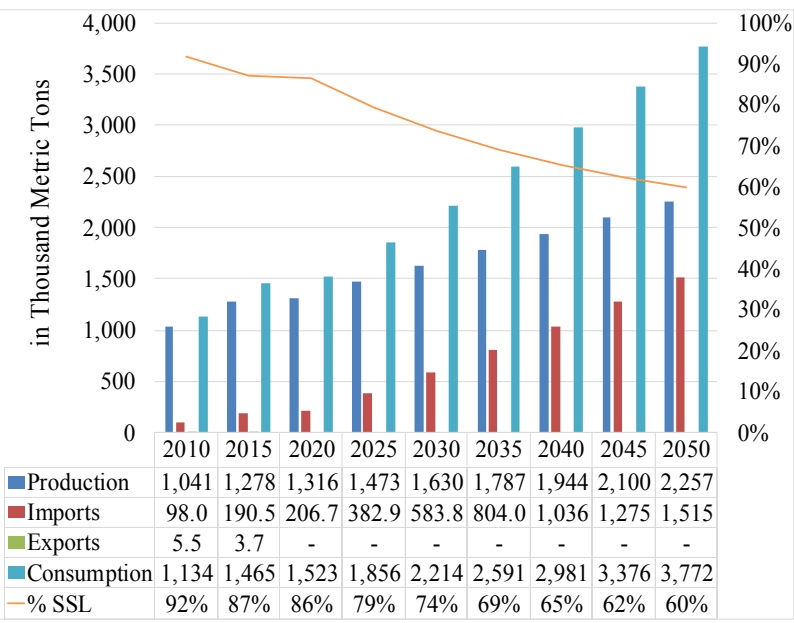

Fig. 5. Supply utilization accounts (2010-2050)

It should be noted that the same feed raw materials are used for food and biodiesel, further increasing food-feed-fuel competition in terms of utilization [33]. To resolve this, the government should be looking already for alternative and 
locally sourced feed inputs. On the other hand, backyard chicken volume contribution will drop from $25 \%$ to $16 \%$, with its slow growth. Perhaps, the industry must focus and identify the areas for improvement on its prevailing practices, methods, and systems and address them to increase productivity. It is also worth noting that the backyard chicken inventory is declining, which shows that backyard needs attention with its low productivity in both count and yield.

TABLE I. VALIDATION OF SIMULATION MODEL

\begin{tabular}{|c|c|c|c|c|c|c|}
\hline \multirow{2}{*}{ Year } & \multicolumn{2}{|c|}{ Local CM consumption } & \multicolumn{3}{c|}{ Local CM production } \\
\cline { 2 - 7 } & Actual* & Simulation* & Error & Actual $^{*}$ & Simulation* & Error \\
\hline $\mathbf{2 0 0 8}$ & 775.0 & 772.5 & 2.5 & 986.6 & 981.8 & 4.8 \\
\hline $\mathbf{2 0 0 9}$ & 798.5 & 812.0 & 13.5 & $1,001.7$ & $1,014.1$ & 12.4 \\
\hline $\mathbf{2 0 1 0}$ & 864.9 & 852.9 & 12.1 & $1,041.9$ & $1,045.8$ & 3.9 \\
\hline $\mathbf{2 0 1 1}$ & 921.8 & 895.2 & 26.6 & $1,089.0$ & $1,077.5$ & 11.5 \\
\hline $\mathbf{2 0 1 2}$ & $1,013.5$ & 939.6 & 73.9 & $1,139.2$ & $1,110.0$ & 29.2 \\
\hline $\mathbf{2 0 1 3}$ & $1,058.9$ & 986.1 & 72.8 & $1,197.4$ & $1,143.2$ & 54.2 \\
\hline $\mathbf{2 0 1 4}$ & $1,143.6$ & $1,034.9$ & 108.7 & $1,210.3$ & $1,177.1$ & 33.2 \\
\hline $\mathbf{2 0 1 5}$ & $1,211.0$ & $1,086.0$ & 125.0 & $1,278.8$ & $1,211.8$ & 67.1 \\
\hline $\mathbf{2 0 1 6}$ & $1,299.9$ & $1,139.6$ & 160.3 & $1,289.4$ & $1,247.2$ & 42.2 \\
\hline $\mathbf{2 0 1 7}$ & $1,498.7$ & $1,195.2$ & 303.5 & $1,344.3$ & $1,282.8$ & 61.5 \\
\hline MAPE & \multicolumn{7}{|c|}{} & \multicolumn{3}{c|}{$*$} & $2.8 \%$ \\
\hline
\end{tabular}

The increasing consumption is driven by population and per capita consumption. Interventions are more feasible in the per capita growth since it can be influenced by changes in eating pattern and lifestyle. In developed economies, awareness on sustainability issues on meat consumption are increasing such as reduction through practice of meatless days [34] and consumption of plant based meat substitutes and alternative protein sources [35]. Perhaps, the industry can also embark on awareness, so that the consumers can somehow have the chance to make sustainable choices. With the model in place, decision makers can use the above implications in integrating proper interventions. Other actions in the forms of technology improvements and consumer awareness can be conceptualized and tested in the model, which can project the relevant variables and check the level of sufficiency at specific timelines. Hence, in the context of planning, the impact of short-term programs and long-term strategies up to 2050 can be evaluated in addressing food security.

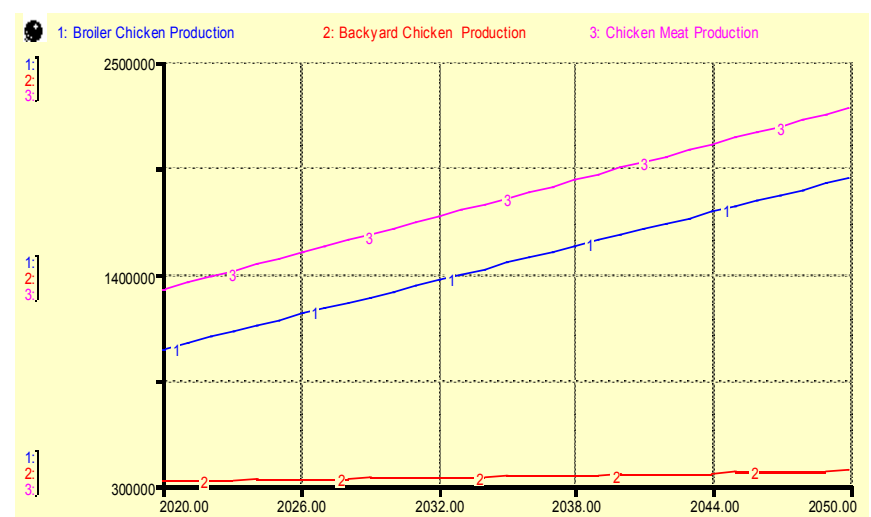

Fig. 6. Broiler and backyard chicken production (2020-2050)

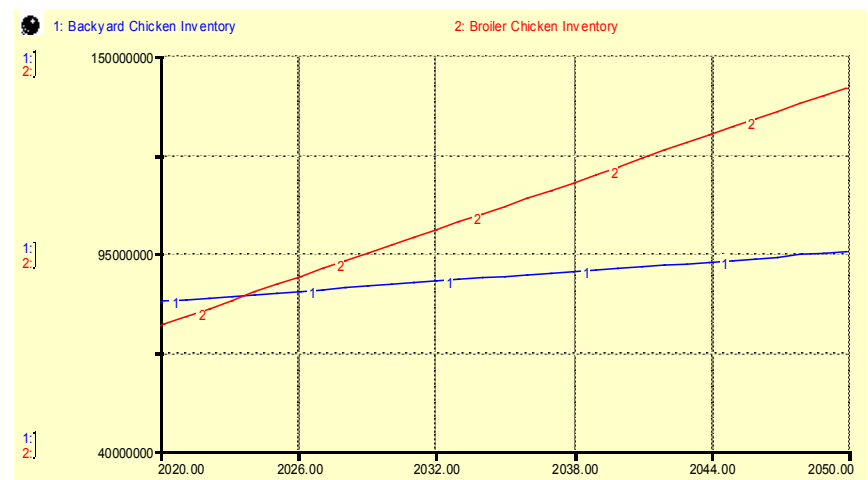

Fig. 7. Broiler and backyard chicken inventory (2020-2050)

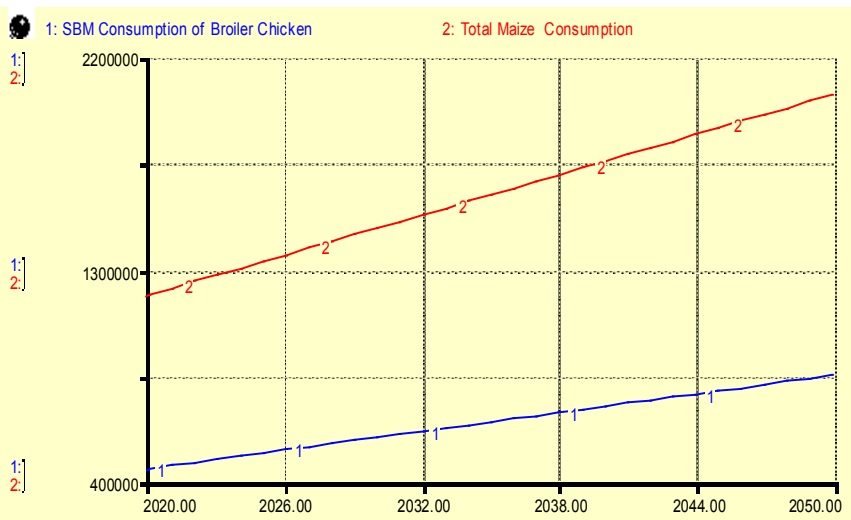

Fig. 8. SBM and maize consumption (2020-2050)

\section{CONCLUSION}

Long-term sufficiency in this study was evaluated by system modeling and computer-based simulation forecasting. The simulated model projected a sufficiency drop to $60 \%$ by 2050 if no interventions take place in production and consumption. With the relevant variables in place in the model, this can be a sound basis in evaluating future scenarios and incorporating possible solutions. In conclusion, the developed dynamic model could be used to facilitate informed decisionmaking. Initially, the process of establishing the model may seem complex in comparison with the traditional forecasting techniques. However, rigor and results can be more significant, especially for dynamic systems in the food and agriculture sectors. This study can encourage a paradigm shift in understanding dynamic factors and give decision-makers a better way of planning and addressing long-term sufficiency and food security concerns.

\section{ACKNOWLEDGMENT}

The authors are grateful for the funding support given by Engineering Research and Development for Technology (ERDT). Due appreciation is also given to Benjamin Rubin for assisting in data processing.

\section{REFERENCES}

[1] OECD, "Meat consumption", available at: http://www.oecd-ilibrary.org

[2] UN, "Sustainable development goals", available at: http://www.un.org/ sustainabledevelopment 
[3] R. Kurt, S. Karayilmazlar, Y. Cabuk, "Important non-wood forest products in Turkey: An econometric analysis", Engineering Technology \& Applied Science Research, Vol. 6, No. 6, pp. 1245-1248, 2016

[4] V. H. M. Nguyen, K. T. P. Nguyen, C. V. Vo, B. T. T. Phan, "Forecast on 2030 Vietnam electricity consumption”, Engineering Technology \& Applied Science Research, Vol. 8, No. 3, pp. 2869-2874, 2018

[5] B. V. B. Prabhu, M. Dakshayini, "Performance analysis of the regression and time series predictive models using parallel implementation for agricultural data", Procedia Computer Science, Vol. 132, pp. 198-207, 2018

[6] K. M. M. E. Dash, O. M. O. Ramadan, W. M. M. A. Youssef, "Duration prediction models for construction projects in middle east", Engineering Technology \& Applied Science Research, Vol. 9, No. 2, pp. 3924-3932, 2019

[7] J. D. Sterman, "System dynamics modeling: Tools for learning in a complex world", California Management Review, Vol. 43, No. 4, pp. 8 25,2002

[8] M. K. Saraji, A. M. Sharifabadi, "Application of system dynamics in forecasting: A systematic review", International Journal of Management, Accounting and Economics, Vol. 4, No. 12, pp. 1192-1206, 2017

[9] W. Srijariya, A. Riewpaiboon, U. Chaikledkaew, "System dynamic modeling: An alternative method for budgeting", Value in Health, Vol. 11, pp. S115-S123, 2008

[10] B. L. Turner, H. M. Menendez, R. Gates, L. O. Tedeschi, A. S. Atzori, "System dynamics modeling for agricultural and natural resource management issues: Review of some past cases and forecasting future roles", Resources, Vol. 5, No. 40Article ID 5040040, 2016

[11] J. P. Walters, D. W.Archer, G. F. Sassenrath, J. R. Hendrickson, J. D. Hanson, J. M. Halloran, P. Vadas, V. J. Alarcon, "Exploring agricultural production systems and their fundamental components with system dynamics modelling”, Ecological Modelling, Vol. 333, pp. 51-65, 2016

[12] E. Suryani, R. A. Hendrawan, T. Mulyono, L. P. Dewi, "System dynamics model to support rice production and distribution for food security", Jurnal Teknologi, Vol. 68, No. 3, pp. 45-51, 2014

[13] A. Sachan, B. S. Sahay, D. Sharma, "Developing Indian grain supply chain cost model: A system dynamics approach", International Journal of Productivity and Performance Management, Vol. 54, No. 3, pp. 187 205,2005

[14] F. H. A. Rahim, N. N. Hawari, N. Z. Abidin, "Supply and demand of rice in Malaysia: A system dynamics approach", International Journal of Supply Chain Management, Vol. 6, No. 4, pp. 234-240, 2017

[15] C. Sampedro, F. Pizzitutti, D. Quiroga, S. J. Walsh, C. F. Mena, "Food supply system dynamics in the Galapagos islands: Agriculture, livestock and imports", Renewable Agriculture and Food Systems, pp. 1-15, 2018

[16] N. Tsolakis, J. S. Srai, "A system dynamics approach to food security through smallholder farming in the UK", Chemical Engineering Transactions, Vol. 57, pp. 2023-2028, 2017

[17] PSA, "CountrySTAT Philippines", available at: http://openstat.psa. gov.ph

[18] J. A. Sison, Feed use estimation: Data, methodology and gaps-The case of the Philippines, AMIS, 2014

[19] Nielsen, "What's in our food and on our mind, ingredient and diningout", Global Ingredient and out-of-Home Dining Trenda Report, 2016

[20] PSA, Agricultural indicators system: Food sufficiency and security, Philippines Statistics Authority, 2019

[21] PSA, Chicken industry performance report, Philippines Statistics Authority, 2017

[22] W. A. Dozier, M. T. Kidd, A. Corzo, "Dietary amino acid responses of broiler chickens", Journal of Applied Poultry Research, Vol. 17, No. 1, pp. 157-167, 2008

[23] IndexMundi, "Philippines soybean meal imports by year", available at https://www.indexmundi.com/agriculture/?country=ph\&commodity=soy bean-meal\& graph=imports

[24] http://www.fao.org/gleam/resources/en

[25] https://vensim.com/vensim-software

[26] https://www.iseesystems.com/resources/help/v1-2
[27] U. Khair, H. Fahmi, S. A. Hakim, R. Rahim, "Forecasting error calculation with mean absolute deviation and mean absolute percentage error", Journal of Physics: Conference Series, Vol. 930, No. 1, Article ID 012002, 2017

[28] R. J. Hyndman, A. B. Koehler, "Another look at measures of forecast accuracy", International Journal of Forecasting, Vol. 22, No. 4, pp. 679688, 2006

[29] N. P. Barbosa, E. S. Christo, K. A. Costa, "Demand forecasting for production planning in a food company", ARPN Journal of Engineering and Applied Sciences, Vol. 10, No. 16, pp. 7137-7141, 2015

[30] Y. Chen, Q. I. Wang, S. Fay, "The role of marketing in social media: How online consumer reviews evolve", Journal of Interactive Marketing, Vol. 25, No. 2, pp. 85-94, 2011

[31] J. L. R. Renteria, T. D. E. Huerta, F. S. T. Pacheco, J. L. G. Perez, R. L. Dorantes, "An electrical energy consumption monitoring and forecasting system", Engineering Technology \& Applied Science Research, Vol. 6, No. 5, pp. 1130-1132, 2016

[32] M. Gilliland, The business forecasting deal: Exposing myths, eliminating bad practices, providing practical solutions, John Wiley \& Sons, 2010

[33] H. P. S. Makkar, "Animal nutrition in a 360-degree view and a framework for future R\&D work: Towards sustainable livestock production", Animal Production Science, Vol. 56, No. 10, pp. 15611568, 2016

[34] J. D. Boer, H. Schosler, H. Aiking, ““"Meatless days” or "less but better"? Exploring strategies to adapt eestern meat consumption to health and sustainability challenges", Appetite, Vol. 76, pp. 120-128, 2014

[35] C. Apostolidis, F. McLeay, "Should we stop meating like this? Reducing meat consumption through substitution", Food Policy, Vol. 65, pp. 74 89, 2016 